\title{
Design digital inclusivo e a vivência democrática: uma experiência criada para todos(as) ou personalizada para cada deficiência?
}

\author{
Inclusive digital design and the democratic living: an experience created \\ for everyone or personalized for each disability?
}

Alessandra Nardoni Watanabe, Ana Claudia Maynardes

cidadania, design inclusivo, digital, integração, personalização

Este artigo apresenta uma discussão de conceitos preliminar de pesquisa em andamento que busca compreender se o design de experiências e produtos digitais que acolha as necessidades de determinado grupo de pessoas com um tipo de deficiência de fato inclui ou se, ao contrário, acaba excluindo por não contemplar uma visão integrada das deficiências que poderia proporcionar uma convivência com as diferenças. Uma vez que os espaços digitais podem ser acessados por qualquer pessoa, ainda que não pertencente ao seu público-alvo, idealmente eles precisam estar preparados para todas elas, diferente do que acontece em alguns ambientes presenciais. Mas isso seria possível? Do ponto de vista da cidadania democrática, o design digital deve investir em uma visão integrada das deficiências ou em acolher necessidades específicas? Em qual das duas abordagens - personalizada ou integrada - o Design deveria apostar pensando em contribuir para uma vivência real da democracia? A pesquisa pretende responder por que é importante - foco exclusivo deste artigo em razão da fase embrionária do estudo - e qual seria um caminho possível apontado pela literatura e pela pesquisa de campo para responder à demanda por uma inclusão efetiva no desenho de soluções digitais.

\section{citizenship, inclusive design, digital, integration, personalization}

This article presents a preliminary concept discussion of ongoing research that seeks to understand whether the design of digital products and experiences that embraces the needs of a particular group of people with a certain type of disability does in fact include or, on the contrary, excludes for not contemplating an integrated view of the disabilities that could provide a coexistence with the differences. Since digital spaces can be accessed by anyone, even if they do not belong to their target audience, ideally they need to be prepared for all of them, differently from what happens in some face-to-face environments. But would that be possible? From the point of view of democratic citizenship, should digital design invest in an integrated vision of disabilities or in addressing specific needs? Which of the two approaches - personalized or integrated - should Design bet on to contribute to a real experience of democracy? The research intends to answer why it is important - the exclusive focus of this article considering the inicial state of the study - and what would be a possible path indicated by the literature and the field research to answer the demand for an effective inclusion in the design of digital solutions.

Anais do $10^{\circ} \mathrm{CIDI}$ e $10^{\circ} \mathrm{CONGIC}$

Kelli C.A.S. Smythe, Rafael de Castro Andrade (orgs.)

Sociedade Brasileira de Design da Informação - SBDI

Curitiba | Brasil | 2021
Proceedings of the $10^{\text {th }} \mathrm{CIDI}$ and $10^{\text {th }}$ CONGIC

Kelli C.A.S. Smythe, Rafael de Castro Andrade (orgs.)

Sociedade Brasileira de Design da Informação - SBDI Curitiba | Brazil | 2021 


\section{Introdução}

A inclusão de pessoas com deficiência (PCDs) nos espaços digitais dialoga com a premissa básica da democracia: a de participação efetiva de todas e todos. Falar sobre experiências democráticas é falar sobre incluir pessoas, com ou sem deficiência, sobre proporcionar uma experiência equivalente, para além do simples acesso, e também sobre uma real inclusão, e não apenas uma integração. É sobre quem não pode ficar de fora, excluído(a) dos ambientes digitais onde a vida acontece hoje. São pessoas com deficiência, pessoas idosas, crianças, pessoas com alguma condição - temporária ou permanente. Todas elas com necessidades próprias que impõem o imperativo da equidade e não da igualdade. E para que isso aconteça é preciso o envolvimento de todas e todos, quer pertençam a esses grupos, quer não.

Vivemos em uma democracia em que todas e todos deveriam ter direito à participação nas diferentes esferas da sociedade e, para que isso aconteça, um importante passo diz respeito às pessoas com deficiência não estarem excluídas de nenhum espaço, principalmente o digital, no qual grande parte das interações, serviços e relacionamentos acontecem atualmente. A democracia só é de fato sentida quando vivenciada e praticada. Partindo dessa premissa e observando o campo do Design digital, a pesquisa se propõe a investigar se, do ponto de vista da cidadania democrática, o desenho de produtos digitais deve investir em uma visão integrada das deficiências ou em recepcionar necessidades específicas. Como acolher a diversidade dentro do universo de pessoas com deficiência e espelhá-la no desenvolvimento de produtos digitais? Reunindo suas diferenças e mostrando por meio do design que elas existem e coabitam o universo digital e, portanto, a sociedade também? Ou, em outro sentido, as segmentando para entregar uma experiência muito mais individualizada e personalizada, tentando considerar melhor cada especificidade? O estudo está se desenvolvendo a partir de pesquisa bibliográfica exploratória sobre design inclusivo e cidadania democrática e, posteriormente, por meio de pesquisa de campo quantitativa e qualitativa com pessoas com e sem deficiências na busca pela resposta ao problema colocado.

\section{Cidadania, diversidade e comunidade}

Uma experiência democrática em sociedade diz respeito ao acesso a diferentes espaços, à participação efetiva nos diversos contextos e a uma vivência permanente baseada nesses valores. A cidadania - ainda que um conceito não estático ou definitivo, uma categoria provisória, dependente do contexto social e em transformação (Morais, 2013, setembro, p. 20920) -, pode ser considerada, de maneira geral, como direitos civis, políticos e sociais de todas e todos. A inclusão de pessoas com deficiência, portanto, é direito e é também um valor de uma democracia e não apenas algo importante que deve ser observado quando possível. Refere-se ao direito de ser tratado(a) com equidade e consideração devido a sua condição de ser humano (PNUD, 2004, p. 69), independentemente de qualquer deficiência.

No apanhado histórico construído por Barreto (1993) sobre cidadania na tentativa se esboçar seu significado moderno, nota-se vários momentos em que a exclusão fazia parte do 
que era compreendido como ser cidadão. Na Revolução Francesa o voto censitário mostrava que a lógica econômica ditaria quem seria um cidadão "ativo" e quem seria "passivo". Parece se aproximar de uma mercantilização de direitos. O mesmo acontece na Revolução Industrial, quando se ampliou o seleto grupo de cidadãos na medida em que se tornavam produtores e consumidores. Na democratização do Estado Liberal há um crescente acesso de eleitores à participação no poder, porém ser um eleitor ainda significava um marcador excludente. O Estado Democrático de Direito nasce a partir do Poder Legislativo passando a legislar também para o não-proprietário em vez de apenas defender os interesses da burguesia, mas isso ainda não significa uma cidadania plena e irrestrita.

Nesses marcos históricos, fica claro o papel do Estado nos avanços sociais, porém, a sociedade civil guarda tanto responsabilidade quanto ele na construção da cidadania. O compromisso democrático pela inclusão cidadã precisaria então ser coletivo e desejado, em vez de individual ou arbitrário. Mouffe (1997) encara a cidadania como uma forma de identificação política do indivíduo que é construída e não simplesmente imposta como um status legal. "O modo como definimos a cidadania está intimamente ligado ao tipo de sociedade e de comunidade política que queremos." (Mouffe, 1997, p. 59).

A cidadania moderna tem tratado da busca coletiva pelo bem comum trazendo à tona a noção de comunidade. Ela carrega consigo a inclusão de uma população e, ao mesmo tempo, a exclusão de outra que não faz parte dessa comunidade, conforme suscita Guarinello (2013, p. 46 apud Morais, 2013, setembro, p. 20911). E é exatamente o que acontece com a comunidade de pessoas com deficiência e as de tantas outras minorias sociais: incluídas em seu meio, mas excluídas do todo e invisíveis à sociedade. Comunidades muitas vezes impenetráveis que conquistam por meio de sua força - que só é possível por sua união - tantos avanços sociais e condições para sua existência, ao mesmo tempo em que reforça sua segmentação e possível exclusão.

Ao se deparar com uma comunidade que não é a sua, o "outro", mais confortável com sua baixa tolerância ao diferente, se sente desconfortável com a possibilidade de perder seus privilégios ao dividir espaço. A valorização do "exclusivo", do "vip", do "grupo seleto" e tantas outras práticas segregadoras ressalta isso. Conforme Parmeggiani escreve em Desabilidade (2018), o encontro com o diverso nos desequilibra, nos faz procurar de volta a segurança e traz a sensação da perda. "[...] diversidade nos obriga a sair de nós para comparar-nos com o outro, e esse movimento para o externo vem percebido como perda de parte da própria identidade e descoberta de uma nova realidade: daí o medo e também a atração." (Parmeggiani, 2018, Habitar fronteiras, I. 420).

\section{O Modelo Social da Deficiência}

A partir dos anos 70 foi possível acompanhar uma onda de movimentos ligados às minorias sociais agregando às concepções de igualdade a ideia de diversidade (Morais, 2013, setembro, p. 20911), já que essa não pressupõe inclusão. Espaços diversos muitas vezes não são 
inclusivos. A diversidade por si só não diz muito. Seu reconhecimento sim, seguido de ações, contribuem para transformações sociais.

A noção de autonomia da pessoa com deficiência foi essencial no caminho para essas transformações. Ela ganhou corpo nos Estados Unidos no final dos anos 60 e início dos 70 com o MVI - Movimento de Vida Independente. Os frutos desse movimento foram se caracterizando no que mais adiante ficou conhecido como Modelo Social da Deficiência (MSD) no campo dos Disability Studies. O pesquisador espanhol Mario Toboso Martín afirma que

El modelo social se constituyó en el núcleo ideológico y discursivo de los Disability Studies. En oposición al modelo médico, interpreta que la discapacidad es el producto de una sociedad discapacitante, y no el resultado de deficiencias ni patologías del cuerpo. (Martín, 2018, outubro, p.785).

Em outras palavras, o MSD entende que o indivíduo deve ser enxergado antes de sua deficiência. Deficiência essa que só se torna uma limitação de fato quando a sociedade - essa sim deficiente - impõe uma barreira. A deficiência de uma pessoa passa então a se multiplicar na proporção da deficiência do ambiente, o que faz com que seja necessário olhar para esse encontro entre o contexto e a pessoa:

No âmbito educativo, fala-se de desabilidade, quando uma pessoa com um déficit, uma falta objetiva, encontra o ambiente físico, social ou cultural. Neste encontro, manifesta-se a desabilidade: a impossibilidade de subir uma escada, a dificuldade de se comunicar ou de apreender. Uma pessoa com deficiência nem sempre tem uma desabilidade. Esta aparece no encontro entre o déficit e o contexto. É a manifestação de uma dificuldade, a do contexto que não está pronto para acolher, mas também a da pessoa que não tem as ferramentas necessárias para interagir com aquele contexto (Parmeggiani, 2018, Introdução, I. 68-72).

Por outro lado, os críticos desse Modelo questionam sobre a desconsideração do corpo nessa complexa equação e isso, segundo Martín (2018, outubro) aponta por meio de estudiosos da área, distancia as pessoas com deficiência de suas próprias experiências:

La ausencia del cuerpo en la teoría de la discapacidad producida por el modelo social conduce a una interpretación de la discapacidad que no se ajusta a la experiencia muy diversa que de la misma tienen las propias personas con discapacidad. Con el fin de rescatar esa diversidad y lograr una comprensión adecuada del sentido social de la discapacidad, se debe emprender el análisis de la misma a partir de la corporalidad específica que conlleva (Corker y Shakespeare, 2002; Ferreira, 2010 apud Martín, 2018, outubro, p.786).

Independentemente da abordagem adotada, a formatação do mundo social por pessoas sem deficiência destinada a essas mesmas pessoas contribui para os problemas em torno da comunidade de PCDs, construindo barreiras, impedindo a sociedade de ser de fato funcional e contribuindo com a exclusão de pessoas com deficiência. (Finkelstein, 2001).

\section{Experiências e produtos digitais inclusivos}

No mundo digital, o desafio das pessoas com deficiência só muda de espaço, uma vez que "internet no se limita a la mera transmisión de información, sino que se convierte en un 
poderoso mecanismo de socialización, de transmisor de ideas y de valores" (Fainholc, 2006, Xavier y Cabecinhas, 2000 apud Agudo, García y Martínez-Hereda, 2020). No ambiente digital, impedir acesso, limitar recursos, não proporcionar uma experiência equivalente e não dar controle impedindo a autonomia ${ }^{1}$ são a regra e também uma forma de exclusão do indivíduo da vivência democrática. Nas exceções a essa regra é possível perceber a necessidade de grande investimento de recursos financeiros, de pessoal e de tecnologia, o que acaba não favorecendo a criação de produtos digitais acessíveis e sua manutenção ao longo do tempo. Além disso, trata-se de um conhecimento extremamente técnico e recente, o que demanda estudo, testes e apoio especializado para que sejam oferecidas experiências confiáveis.

Aguardar o interesse da sociedade nessa temática ou esperar que ela compreenda suas nuances continua a gerar uma sociedade disfuncional. Por isso, a mudança precisa começar pelas pessoas jurídicas e não só por ações isoladas de pessoas físicas. Quando todos os sites e produtos digitais foram concebidos acessíveis em sua origem, conforme o desenho universal previsto na Lei Brasileira de Inclusão - Lei n. 13.146/2015 -, só então pessoas com e sem deficiência estarão, necessariamente, vivenciando, nesse aspecto, a democracia como ela deveria ser, inclusiva.

É importante ressaltar também que a visão de que os saberes relacionados à inclusão beneficiam apenas pessoas com deficiência é equivocada. Alguém sem deficiência e que prefere, por opção ou circunstância, ler as legendas em vez de ouvir um áudio, por exemplo, ou prefere escrever em vez de falar ao telefone é também contemplado(a) com ações inclusivas. Segundo a ativista do design social Elise Roy, essas tecnologias criadas para o universo de PCDs mudaram, inclusive, a forma como todos se relacionam ${ }^{2}$, a exemplo das mensagens de texto, que passaram a ser a principal forma de comunicação cotidiana. Volta-se, então, para a dimensão universal, coletiva e integral do tema tratado aqui.

Do ponto de vista capitalista, parece estranho pensar na exclusão como caminho, já que a inclusão trata de mais (ou todos os) consumidores dentro do sistema econômico. O design inclusivo pode mostrar que a exclusão é cara e a inclusão, lucrativa. Usualmente, destinam-se escassos recursos financeiros e de pessoal em prol de uma maioria tida como economicamente ativa, excluindo como público muitas pessoas com qualquer tipo de deficiência como se nenhuma estivesse no mercado de trabalho ou como se não representassem um grande público consumidor, direto ou indireto por meio de seus tutores. Mais pessoas participando da sociedade significa necessariamente mais consumidores. Além disso, as empresas acabam tendo mais gastos financeiros empregados em adaptações de projetos a posteriori ou até gastos judiciários e honorários advocatícios em casos de processos judiciais em razão do impedimento do acesso e/ou participação dessas pessoas a seus

\footnotetext{
${ }^{1}$ Contra os princípios do design inclusivo desenvolvidos por Henny Swan, lan Pouncey, Heydon Pickering e Léonie Watson, que pode ser recuperado em https://inclusivedesignprinciples.org/.

${ }^{2}$ Em seu TEDx de setembro de 2015, recuperado em https://www.ted.com/talks/elise_roy_when_we_design_for_disability_we_all_benefit?utm_campaign=Quarentena+Peres troika\&utm_content=Elise+Roy\%3A+When+we+design+for+disability $\% 2 \mathrm{C}+$ we+all+benefit+\%7C+TED+Talk+\%281\%29 \&utm_medium=email\&utm_source=EmailMarketing\&utm_term=Tamo+Junto+-+Materiais+semana+2.
} 
produtos ou serviços. E ainda, não se pode esquecer que a responsabilidade social também está ligada aos lucros de uma empresa.

\section{Esboçando o caminho da visão integrada das deficiências}

A democracia não está garantida, assim como a cidadania e a inclusão também não estão. Ter seus direitos listados em lei está longe de significar seu exercício efetivo e o gozo de seus efeitos. Políticas inclusivas não são sinônimo de práticas inclusivas. Reunir-se em uma comunidade pode contribuir para o alcance desses direitos, ao passo que também constrói disputas e barreiras a outros grupos necessários à construção de uma sociedade que partilhe de uma mesma linguagem que abrace o diverso.

Quando a própria comunidade também está dividida, em seus nichos menores, com sua linguagem própria e costumes próprios, o desafio do designer fica ainda maior. O universo que parecia ser conhecido para desenvolver para a comunidade de pessoas com deficiência parece insuficiente diante das especificidades da comunidade surda, da cega, da cadeirante, da autista e de tantas outras.

É interessante notar que quando alguém que não pertence a uma determinada comunidade se depara com um produto desenvolvido para ela, a comunidade "contemplada" passa a tomar lugar no mundo pela simples percepção de sua existência pela "não contemplada". Fica evidente aí o papel do designer como um ator social (Manzini, 2019, p.15). Um produto que atende a necessidades diferentes que as do seu público, no Design, pode ser considerado ruim ou equivocado, mas traz consigo uma mensagem, um manifesto: essa outra comunidade ou parte de uma mesma comunidade existe, é preciso olhar para ela. Estar em um ambiente digital cercado pela preocupação com diferentes necessidades pode significar vivenciar a democracia mesmo que naquele breve instante, clique ou acesso. Não se trata de um retorno à Era Industrial da reprodução massificada de produtos que atendem a todos, mas também não diz respeito à continuidade da produção ultra segmentada e personalizada que cria bolhas de insensibilidade, ignorância e intolerância.

\section{Referências}

Agudo, A. A., García, E. G., Martínez-Hereda, N. (2020). Desafíos para una ciudadanía inclusiva: competencia digital entre adultos mayores y jóvenes. Comunicação, mídia e consumo. 17(48), 11-33.

https://doi.org/10.18568/CMC.V17148.2247

Barreto, V. (1993). O conceito moderno de cidadania. Revista de Direito Administrativo. 192:29-37.

Finkelstein, V. (2001). The social model of disability repossessed. Manchester Coalition of Disabled People, 1-5. Recuperado em 22 dezembro, 2019, de https://disabilitystudies.leeds.ac.uk/wp-content/uploads/sites/40/library/finkelstein-soc-mod-repossessed.pdf. 
Lei n. 13.146, de 6 de julho de 2015 (2015). Institui a Lei Brasileira de Inclusão da Pessoa com Deficiência (Estatuto da Pessoa com Deficiência). Brasília, DF. Recuperado em 10 abril, 2021, de http://www.planalto.gov.br/ccivil_03/_ato2015-2018/2015/lei/l13146.htm

Manzini, E. (2019). Design: quando todos fazem design: uma introdução ao design para inovação social (reimpressão). São Leopoldo, RS: Unisinos (Obra original publicada em 2015).

Martín, M. T. (2018). Diversidad funcional: hacia un nuevo paradigma en los estudios y en las políticas sobre discapacidad. Política y Sociedad. 55(3) 783-804.

https://doi.org/10.5209/POSO.56717

Morais, I. A. (2013). A construção histórica do conceito de cidadania. Anais do XI Congresso Nacional de Educação - EDUCERE, Curitiba, PR, Brasil. 20908-20922.

Mouffe, C. (1997). A cidadania democrática e a comunidade política. UNESP-FCL. 59-68.

Parmeggiani, R. (2018). Desabilidade (1a ed.). São Paulo: Nós.

PNUD. (2004). A Democracia na América Latina: rumo a uma democracia de cidadãs e cidadãos. São Paulo: LM\&X.

\section{Sobre as autoras}

Alessandra Nardoni Watanabe, mestranda, UnB, Brasil <alessandra.nw@gmail.com> Ana Claudia Maynardes, Dra, UnB, Brasil <anacmay@gmail.com>. 